\title{
Teacher Informal Collaboration for Professional Improvement: Beliefs, Contexts, and Experience
}

\author{
Beatrice Avalos-Bevan ${ }^{1}$ and Martín Bascopé ${ }^{2}$ \\ ${ }^{1}$ Centre for Advanced Research in Education (CIAE), University of Chile, Santiago, Chile \\ ${ }^{2}$ P. Catholic University of Chile, Campus Villarrica, Santiago, Chile \\ Correspondence should be addressed to Beatrice Avalos-Bevan; bavalos254@gmail.com
}

Received 2 April 2017; Accepted 24 August 2017; Published 12 October 2017

Academic Editor: Jukka Husu

Copyright @ 2017 Beatrice Avalos-Bevan and Martín Bascopé. This is an open access article distributed under the Creative Commons Attribution License, which permits unrestricted use, distribution, and reproduction in any medium, provided the original work is properly cited.

\begin{abstract}
The article presents results of a study on teachers' views, beliefs, and experience on school-based informal collaboration for professional improvement. It explores the relationship of teacher beliefs in the collective efficacy of their colleagues and school's capital and culture with their beliefs and experience in school-based collaborative learning. The key source of evidence used is a survey of 1025 primary and secondary teachers in three geographical regions of Chile. Main results show that teachers hold positive beliefs about the collective efficacy of their colleagues and students in their schools but more negative ones regarding the contribution of parents. In terms of collaboration, teachers hold positive beliefs in general about its role for professional learning but indeed engage more in the "weaker" types of collaboration such as "sharing ideas" and "talking about teaching problems" and less in the more demanding ones such as "mutual lesson observation" and "team teaching." Differences in teachers' views, beliefs, and experience were examined in terms of level of teaching (primary/secondary), urban/rural location, school type (public and private), and school size.
\end{abstract}

\section{Introduction}

The professional learning of teachers takes place in the continuum of formal pre- and in-service teacher preparation and through a variety of less formal interactions occurring in communities of practice or professional learning communities and teacher networks as well as through personal reflection on teaching experience $[1,2]$. In relation to less formal instances of professional learning, recent research on teacher workplace learning has centred on the role of teacher collaboration and how teachers describe these experiences [3], on how they interact in school-based groups focused on teaching improvement [4], on differences between forms of collaboration by types of schools and country contexts $[5,6]$, and on conditions and factors affecting informal and collaborative learning $[7,8]$ (Lohman 2009).

Informal learning through teacher collaboration has been recognised as important in international research, for example, in the OECD directed TALIS study [9] which found that collaboration connected with higher levels of teacher self-efficacy in almost all participating countries as well as with higher job satisfaction in two out of three countries [10]. In Chile, school-based teacher collaboration for the purposes of learning and improvement has been recognised and supported at policy level [11] and more recently in a new law on professional development rights and opportunities. Specifically, the law recognises teamwork and collaboration as a criterion for teacher evaluation [12].

Beyond acknowledging in principled way the value of teacher formal and informal collaboration, it is important to understand how such collaboration occurs, what are the factors that contribute to it, and its value and enactment by teachers in diverse school cultures and organizational settings. This article deals with how teachers refer to and participate in collaborative activities across a diversity of schools and geographical contexts in Chile. It is based on key results from a survey of over one thousand teachers that centred on their views and beliefs about professional 
learning through teacher collaboration; on beliefs about their colleagues' and school community's capital as a source of learning; and on actual engagement in school-based teacher collaboration in the different types of schools in which they worked.

The article feeds into the international literature on teachers by focusing on teacher collaboration in a higher-income country with still unsatisfactory student learning results and unsatisfactory teacher working conditions as evident from different studies PISA 2015 [13], TIMSS 2015 [14], and TALIS 2013 [9].

\section{Conceptual Framework and Literature Review}

In framing the study we relied on the concept of teacher professionalism, highlighting how teachers see themselves (identity) and how they interpret and carry out their work on the basis of what they know and believe in (practice of teaching). We centred on teachers' occupational discourse as distinct from the managerial discourse about teachers of policy-makers and educational authorities [15]. Teacher discourse about professional development and collaboration draws on their knowledge and capacities described by Hargreaves and Fullan [16] as "professional capital." While this "capital" refers to individuals it is also applicable to teachers as a group.

Teacher initial preparation and continued participation in professional development activities increase the fund of knowledge and practical experience of teachers and their capital. Throughout these processes they experience changing needs [17] that require different kinds of learning. Thus, as teachers move ahead in experience they are less pressed to improve their content knowledge and skills and more open to experimenting with new teaching forms and tools and to exchanges with others in the process. In this respect, teacher professional learning can be described as a social generative process that extends from the individual through the community and the social environment [18], making formal and informal collaboration an important part of the process. Teacher collaborative learning in turn may be sketched as a continuum covering occasional interactions or "opportunistic teacher encounters" with the purpose of information or assistance, closer exchanges such as storytelling and sharing of good practices, and goal-directed team work which increasingly relies on teacher-to-teacher initiative and autonomy $[1,19]$.

The extent to which teachers in given school situations effectively engage in genuine collaborative activities as opposed to those "contrived" by the school administration [1] is associated with their own professional beliefs about teaching and student learning. These beliefs usually focus with preference on a subject matter orientation or one that emphasises student characteristics and learning styles, leading to more direct or more constructivist forms of teaching [20]. There is some evidence that teachers holding to a more directive view of teaching based on subject matter knowledge and its faithful communication to students will be less inclined to collaborate with other teachers, while those with a more student-centred approach to teaching would be more disposed to share and learn through collaboration (Becker and Riel and Van Veen et al. in [20]).

From another angle, the disposition to learn from collaboration with others is related to the belief a teacher might have that his or her colleagues have something to offer, as well as to beliefs about the school community's potential and actual educational orientation. These beliefs have been expressed and measured using the concept of "collective teacher efficacy" [21] and of "school capital" [22]. As described by Goddard et al. [21, p. 480], collective efficacy refers to the perception that individual teachers have about their colleagues being able to exert a positive effect on students as well as to feelings of trust in them, both of which are considered preconditions for working together and learning from each other (Goddard, Hoy, and Woolfok Hoy, 2015).

Taking the school as a community comprising not only teachers but also parents and students, Belfi et al. [22] extend the concept of collective efficacy to beliefs in the "social capital" of schools. Social capital beliefs express the extent to which parents and students (as well as teachers) are seen to contribute to the school's mission and educational purposes maintaining a climate of "trust, support, norms, and values." According to Belfi et al. [22] social capital beliefs also mediate between teacher perceptions of the effects of socioeconomic composition on student results and their own perceived collective efficacy. Thus, a higher perception of the school's social capital would include more positive beliefs among teachers about the capacity of their colleagues to raise the educational possibilities of disadvantaged students (collective teacher efficacy). Close to the concept of social capital though broader is the notion of school cultures as providing a basis for teacher collaboration [23].

Beyond these factors impacting on a teacher's inclination to work collaboratively, there are conditions highlighted in research that hinder collaboration. These are of diverse types, among which lack of appropriate spatial conditions in the school and nonfavourable leadership are repeatedly mentioned in different studies and contexts [1, 3, 24]. Also noted are teacher factors such as unwillingness to collaborate with others, personality clashes, and holding of different pedagogical orientations [1]. Teacher collaboration is affected as well by structural factors such as teacher contracts and available time and by pressures derived from testing and standardisation [1].

Figure 1 illustrates the conceptual relationships that guided the framing of the study and interpretation of its results.

Holding to the conceptual framework (Figure 1), this article examines teacher collaboration in Chile from the following perspectives: (a) how important is teacher collaboration perceived to be and what is the actual experience of school-based teacher collaboration (formal and informal) that teachers declare? (b) What beliefs about teaching and learning known to affect teacher collaboration do teachers hold? (d) What beliefs about collective efficacy of their colleagues and the social capital of their schools known to affect teacher collaboration do teachers hold? (e) How do 


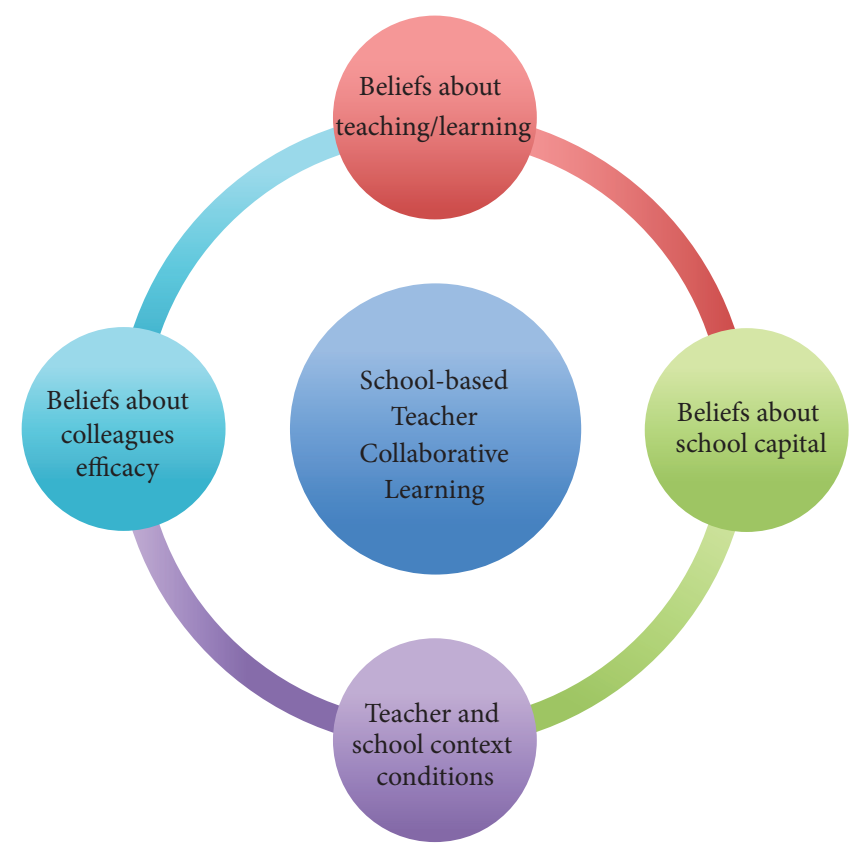

FIgURE 1: Central concepts and relations guiding the study.

teachers' experience and views on collaboration differ by factors related to teaching level, school location, rural/urban condition, management type, and size.

\section{The Study}

The study was carried out in three of the 15 regions in which Chile is administratively divided. The largest is the Metropolitan Region with the capital city of Santiago and a population of over seven million people. The second largest region in the study is the VIII Region also known as the Biobio Region with over two million people, and the third one is the much smaller IX Region or the region of Araucanía with a population close to 990,000 people. Besides Santiago, the major cities involved are Concepción in the Biobio Region with over one million people and Temuco in the Araucanía Region with 410,000. The Chilean school system consists of municipal publicly funded schools and private subsidised and private independent schools. Municipal schools have 36.8\% of the student population while private subsidised schools have been increasing their student numbers to a current $55.2 \%$ [25]. There is strong socioeconomic segregation by type of school management, with municipal and a proportion of private subsidised schools attending students from more deprived families, making Chile one of the OECD countries with higher levels of school segregation [26]. All three types of primary and secondary schools in the three regions were considered for the study.

We used a mixed-methods design involving a survey and a set of eight case studies in the regions, but in this article we mainly rely on the survey data. We selected a proportionally representative sample of 303 schools, both primary and secondary. We gained acceptance for the survey from school authorities in 254 of the sampled schools (83.8\%) of which a third were located in the Metropolitan Region (32.8\%). Acceptance from private schools was lower (43.7\%). Within each sampled school we randomly selected a proportion of teachers for participation in the survey on the basis of gender, age, and main subject area taught. We achieved a $100 \%$ response rate from teachers in the Biobio and Araucanía regions compared to $74.7 \%$ in the Metropolitan Region. The lower rates of participation of Metropolitan Region teachers can be partly explained by the number of demands on them in terms of studies as well as other external pressures. Altogether, we achieved a total representation in relation to the achieved sample of $86.8 \%$ as shown in Table 1 .

3.1. The Teachers Studied. Reflecting the distribution of the teacher population in Chile, most were women (68.3\%). Just over a quarter were 30 years old or less (27.1\%), half of them were aged between 31 and 50 years (50.2\%), and the rest ranged between 51 and 61 years $(22.7 \%)$. These teachers taught in primary level schools of eight-year duration (45.7\%), and in the science/humanities (17\%) and technical vocational branches $(3.7 \%)$ of secondary schools, as well as both in primary and in secondary levels (14.3\%). A number of teachers were also teaching in special education schools (14.1\%) and in other areas such as adult education (5.1\%). By type of school management $42.5 \%$ were working in municipal schools and $50 \%$ in the private subsidised sector. The rest taught in private schools.

Finally, over two thirds of teachers (77.7\%) had been 10 years or less in their school. The rest had taught in the same school between 11 and 15 years (8.7\%), between 16 and 24 years $(8.9 \%)$, and 25 years or more $(4.8 \%)$. 
TABLE 1: Distribution of teachers sampled by type of school ${ }^{*}$ and geographical region $(N=1023)$.

\begin{tabular}{|c|c|c|c|c|}
\hline & \multicolumn{4}{|c|}{ Regions } \\
\hline & Metropolitan $(N=553)$ & Biobio $(N=319)$ & Araucanía $(N=151)$ & Total \\
\hline Municipal & $40.5 \%$ & $43.2 \%$ & $16.3 \%$ & 435 \\
\hline Private subsidised & $63.8 \%$ & $21.5 \%$ & $14.7 \%$ & 511 \\
\hline Private & $66.2 \%$ & $27.3 \%$ & $10.5 \%$ & 77 \\
\hline Total & $42.5 \%$ & $50.0 \%$ & $7.5 \%$ & 1023 \\
\hline
\end{tabular}

${ }^{*}$ Two teachers belonging to public schools with a special type of school management were not included in this classification.

\section{Data Sources}

The survey which provides the main source of data for this paper consisted of 20 items covering personal and professional information and scaled items inquiring about beliefs on teaching and learning, views about professional development, and beliefs about collective teacher efficacy and about the social capital of their school community as well as extent of participation in professional collaboration in their school. We refer to these in more detail below.

Teachers' beliefs about teaching and learning were examined on the basis of an instrument developed by De Vries et al. [20] for this purpose. The statements, on a 4-point scale, assess the importance in teaching and learning of a subject matter orientation, student understanding, order and discipline, active learning, and acknowledgment of student differences. Also on the basis of another De Vries et al.s [27] instrument we examined the degree of importance given to professional development by way of attending activities in and out of the school, as well as school-based individual and collaborative activities among teachers.

Beliefs about the school community in which teachers had the highest number of contractual hours were elicited on the basis of items forming part of the "teacher collective efficacy" instrument developed by Goddard et al. [21], the "school social capital" scales in Belfi et al. [22], and "school culture" in Forte and Flores [3]. From the "revised collective teacher efficacy" [21] instrument we used seven items dealing with beliefs about teacher competencies and we used all the items in Belfi et al. [22] school's social capital instrument. In turn for school culture we used items in Flores et al. (2014) instrument indicating teachers views on responsibilities, participation, and opportunity to contribute. Finally, regarding teacher's actual frequency of involvement in school-based collaborative activities we used relevant items from the TALIS 2013 survey [9] in which Chilean teachers had participated.

The questionnaire was tried out with nine teachers from the three types of schools (municipal, private subsidised, and private) including a rural school. There were minor changes to the format of some of the survey items as well as improvement of procedures for making contact with the sampled schools and teachers. The questionnaire was administered electronically after schools and teachers had been approached directly by assistant staff and assented to respond. Teachers who were in schools with connectivity problems were given paper forms of the questionnaire.

\section{Methods of Analysis}

Besides a descriptive analysis of the data and considering that all the questionnaire scales were of the Likert type we used exploratory factor analysis with a maximum likelihood method followed by varimax orthogonal rotation to calculate scores and group statements scoring more than 0.3 [28]. After identifying the factors we calculated a measure of reliability for each factor using Cronbach alphas [29]. All the coefficients and scores are considered and displayed in the Main Results.

Along with this, we calculated descriptive statistics (mean and standard deviation) for each factor and the statistical significance of differences between factors, using normal confidence intervals. We looked for statistically significant differences by comparing the mean of each factor with a confidence interval at a 95\% level, without overlapping. Means that showed no interval overlapping were considered as significantly different. Finally, we crossed the teacher collaboration factors with teacher and school characteristics as well as geographical location and calculated statistical significance of differences.

\section{Main Results}

We examine here some of the key elements regarding teacher collaboration for professional development purposes on the basis of the following:

(1) Teacher views about school-based professional development and the extent to which they had actually engaged in different types of professional development in the past twelve months

(2) Individual and institutional factors possibly affecting teachers' involvement in professional collaboration: beliefs about teaching, perceived collective teacher efficacy, and perceived school social capital

(3) Differences in teacher views and involvement in collaboration in terms of teaching level and school characteristics (regional location, urban/rural condition, type of school management, and size).

6.1. Teacher Beliefs about Professional Development and Actual Opportunities for School-Based Collaborative Professional Work. We inquired about the kind of professional development activities that teachers considered important on 
TABLE 2: Beliefs about professional development (degree of importance: $1=$ not important; 4 = very important) ${ }^{*}$.

\begin{tabular}{|c|c|c|}
\hline & Component items & $\begin{array}{c}\text { Factor } \\
\text { loadings }\end{array}$ \\
\hline \multirow{3}{*}{$\begin{array}{l}\text { Factor 1: lesson observation } \\
\text { Mean: 3.15; SD: } 0.54 \\
\text { Cronbach Alpha: } 0.7748\end{array}$} & Look at videos of my lessons to improve my practice & 0.684 \\
\hline & Visit another colleague's lesson to learn from him/her & 0.850 \\
\hline & Ask another colleague to observe my lesson to get his/her feedback & 0.848 \\
\hline \multirow{3}{*}{$\begin{array}{l}\text { Factor 2: working with colleagues } \\
\text { Mean: 3.32; SD: } 0.65 \\
\text { Cronbach Alpha: } 0.8678\end{array}$} & Prepare lessons with other colleagues & 0.903 \\
\hline & Try out new ways of teaching with other colleagues & 0.883 \\
\hline & Engage in team teaching with other colleagues & 0.899 \\
\hline \multirow{3}{*}{$\begin{array}{l}\text { Factor 3: reflection based on case analysis } \\
\text { and assessment results } \\
\text { Mean: 3.56; SD: } 0.46 \\
\text { Cronbach Alpha: } 0.6941\end{array}$} & Analyse intensively a teaching problem before deciding on a solution & 0.808 \\
\hline & Examine my students' work to see if my teaching approach worked & 0.726 \\
\hline & Use data from my students learning results to re-orient my teaching & 0.733 \\
\hline \multicolumn{3}{|c|}{ Model fit statistics: RMSEA: 0,072; CFI: 0,987; WRMR: 1,061 } \\
\hline
\end{tabular}

* Based on questionnaire in De Vries et al. [20].

TABLE 3: Professional interchange within schools as reported by teachers $(1=$ never; $2=$ once a year or less, $3=2-4$ times a year; $4=5-10$ times a year: $5=1-3$ times a month; $6=$ once a week or more) ${ }^{*}$.

\begin{tabular}{|c|c|c|}
\hline & Component items & $\begin{array}{l}\text { Factor } \\
\text { loadings }\end{array}$ \\
\hline \multirow{4}{*}{$\begin{array}{l}\text { Factor 1: discuss and work together } \\
\text { Mean: 4.6; SD: } 1.1 \\
\text { Cronbach Alpha: } 0.795\end{array}$} & $\begin{array}{l}\text { Engage in discussions about the learning development } \\
\text { of specific students }\end{array}$ & 0.778 \\
\hline & $\begin{array}{l}\text { Hold informal conversations with other teachers on } \\
\text { professional themes }\end{array}$ & 0.558 \\
\hline & $\begin{array}{l}\text { Work with other teachers to ensure common standards } \\
\text { in the assessment of student progress }\end{array}$ & 0.831 \\
\hline & $\begin{array}{c}\text { Develop student assessment instruments (i.e. criteria, } \\
\text { portfolios, tests) }\end{array}$ & 0.649 \\
\hline \multirow{2}{*}{$\begin{array}{l}\text { Factor 2: observe other teacher lessons and engage in joint activities } \\
\text { Mean: } 2.98 \text {; SD: } 1.4 \\
\text { Cronbach Alpha: } 0.7748\end{array}$} & Observe other teacher's classes and provide feedback & 0.806 \\
\hline & $\begin{array}{c}\text { Engage in joint activities across different classes and age } \\
\text { groups (e.g. projects) }\end{array}$ & 0.714 \\
\hline \multicolumn{3}{|c|}{ Model fit statistics: RMSEA: 0,098; CFI: 0,947; SRMR: 0,042 } \\
\hline
\end{tabular}

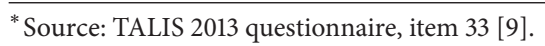

a four-point scale based on a list in De Vries et al. [20]. After factor analysis of responses to all 18 items we were able to establish a clustering around three types of activities related to professional development. As shown in Table 2 teachers' main preferences were for activities that involve individual reflection based on case analysis and assessment results. Lower in preference were activities involving actual work with colleagues such as "preparing lessons with colleagues" or "engaging in team teaching" and in third place was learning from lesson observation.

Besides learning about the degree of importance teachers grant to diverse forms of professional development we inquired about the frequency with which they actually engaged in school-based professional collaborative activities. For this purpose we used items of the TALIS 2013 teacher questionnaire [9] with results as shown in Table 3.

As illustrated in Table 3 there are certain types of interactive activities in which teachers tend to engage more frequently such as informal conversations among themselves and discussion of learning results of specific students. On the other hand, half of the teachers $(50,5 \%)$ never or rarely observed each other's classes and just over a third (37.3\%) never or rarely engaged in joint activities such as project development. Nevertheless, these rates of engagement in collaborative activities are higher than those reported by Chilean teachers participating in the TALIS 2013 study (see Table 4).

6.2. Factors Associated with Professional Development and Teacher Collaboration. We now turn to examine those factors that the literature on teacher professional development preferences and opportunities has identified as affecting teacher collaborative learning. These centred around personal factors such as beliefs about teaching and learning as well as corporate or social factors related to the school environment where teachers work for the most of their time.

6.2.1. Beliefs about Teaching. The 14 items measuring teacher beliefs about teaching were aptly classified into two factors that distinguished teaching as being oriented to student learning competences and skills and teaching as being centred on subject matter and content learning (as in [20] study). As shown in Table 5 on average teachers rated almost equally 


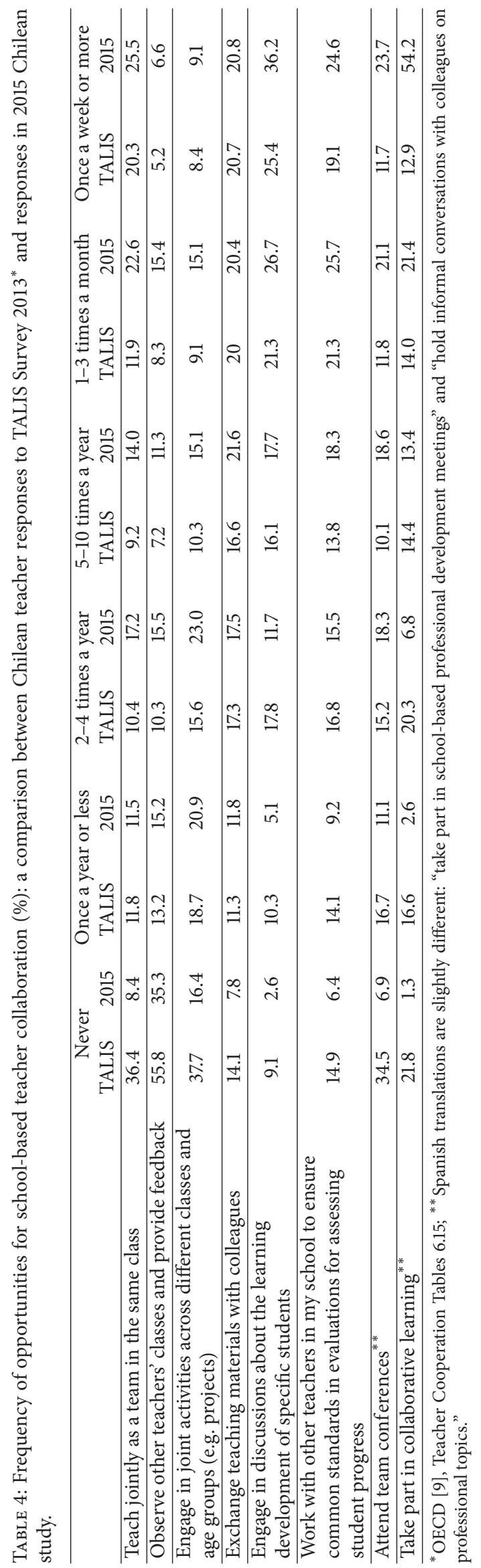


TABLE 5: Teacher beliefs about the focus of teaching for learning $(1=\text { not important; } 4=\text { very important })^{*}$.

\begin{tabular}{|c|c|c|}
\hline & Component items & Factor loadings \\
\hline \multirow{4}{*}{$\begin{array}{l}\text { Factor 1: student oriented } \\
\text { Mean: } 3,74 \text {; SD: } 0,36 \\
\text { Cronbach Alpha: } 0.728\end{array}$} & Students, where relevant learn cooperatively in groups & 0,641 \\
\hline & Students develop their skills and competences & 0,832 \\
\hline & To relate to students' own knowledge and experience & 0,880 \\
\hline & To consider the differences in aptitudes and interests among students & 0,727 \\
\hline \multirow{4}{*}{$\begin{array}{l}\text { Factor 2: subject matter oriented } \\
\text { Mean: 3.67; SD: } 0.42 \\
\text { Cronbach Alpha: } 0.7816\end{array}$} & Pass on subject matter to students & 0,799 \\
\hline & The content of my lessons should be good & 0,767 \\
\hline & Students acquire knowledge & 0,800 \\
\hline & Students learn the content of my subject matter & 0,872 \\
\hline
\end{tabular}

*Items based on De Vries et al. [20] questionnaire.

TABLE 6: Degree of agreement on collective teacher efficacy $(1=\text { not at all; } 7=\text { fully agree })^{*}$.

\begin{tabular}{|c|c|c|}
\hline & Component items & $\begin{array}{c}\text { Factor } \\
\text { loadings }\end{array}$ \\
\hline \multirow{3}{*}{$\begin{array}{l}\text { Factor 1: positive view } \\
\text { Mean: 5.57; SD: } 1.09 \\
\text { Cronbach Alpha } 0.7778\end{array}$} & Teachers in this school are able to get through to difficult students & 0,831 \\
\hline & Teachers in this school believe every student can learn & 0,834 \\
\hline & Teachers in this school use a variety of teaching methods & 0,576 \\
\hline \multirow{4}{*}{$\begin{array}{l}\text { Factor 2: negative view } \\
\text { mean: } 2.76 \text {; SD: } 1.69 \\
\text { Cronbach Alpha } 0.8788\end{array}$} & Teachers in this school think there are students no one can reach & 0,682 \\
\hline & Teachers here don't have the skills needed to produce meaningful student learning & 0,783 \\
\hline & Teachers in this school do not have the skills to deal with student disciplinary problems & 0,866 \\
\hline & If a student doesn't want to learn, teachers here give up & 0,893 \\
\hline
\end{tabular}

Model fit statistics: RMSEA: 0,069; CFI: 0,968; SRMR: 0,034

* Items based on Goddard et al. [21] questionnaire.

the importance of student competences and skills as well as insuring the achievement of content learning.

6.2.2. Beliefs about the Social Capital of the School. The concept of school capital describes the affordances provided by the school as a whole that affect the well-being of teachers and their professional learning as well as student achievement and that have been considered in studies that referred to teachers and their development ([22], TALIS in [9], and [3]). Following Belfi et al.s [22] concept of school social capital we described it as the opportunity for growth and exchange offered by the community of teachers, parents, and students. Further, we considered this capital to be enhanced by a culture of cooperation, respect, stimulation, and concerns for diversity and inclusion. In what follows we examine the sampled teachers' beliefs about the collective efficacy of colleagues in their school as well as beliefs about the contribution to the school ethos of parents and students.

6.2.3. The Collective Efficacy of Teachers. This interesting concept derived from Bandura [30] extends to the teaching body of a school the notion of self-efficacy or the belief in one's capability to perform what is appropriate or required in professional terms. Following Goddard et al. [21] we focused on teachers' views about the "collective capability" of their colleagues to influence student achievement and behaviour. Teacher responses clearly supported a positive view of teachers' collective efficacy rather than a negative one as shown in Table 6. In fact, over half of the teachers agreed much/very much about their colleagues being able to reach out to difficult students (55.9\%), believing that every student can learn (62.4\%) and using a variety of methods for teaching (58.0\%). On the other hand they disagreed very much/much about teachers not having the capacity to get students to learn in a significant way (63.6\%) or giving up if a student is not willing to learn $(63.7 \%)$. Thus, on the whole respondents had a positive perception of the school's teaching body efficacy.

6.2.4. Parents and Students. We inquired about teacher views on the role and participation of parents in school affairs and on how teachers and authorities interact with them and respect their views and concerns. As shown in Table 7 , the surveyed teachers differed in their beliefs about the contribution of parents and students to school's social capital. Fewer teachers held a positive view (very much in agreement) on parents as supportive of their children's learning (22.2\%) and as assisting them to develop good study habits (17\%). Also fewer teachers considered that the school could count on parental involvement (17\%). Conversely, teachers indicated a higher level of agreement about the schools' students: they were trustworthy $(55.6 \%)$, were responsible in carrying out their assigned tasks (41.6\%), respected those who achieve good grades $(51 \%)$, and cared for each other (44\%). Table 7 
TABLE 7: Degree of agreement about quality of parent and student role in school. Teachers' views $\left(1=\right.$ not at all; $7=$ very much in agreement ${ }^{*}$.

\begin{tabular}{|c|c|c|}
\hline & Component items & Factor loadings \\
\hline \multirow{4}{*}{$\begin{array}{l}\text { Factor 1: teacher views on parents } \\
\text { (i) Mean: 3.87; SD: } 1.56 \\
\text { (ii) Cronbach Alpha: } 0.7927\end{array}$} & Parental involvement supports learning & 0,894 \\
\hline & Parents are reliable in their commitments & 0,942 \\
\hline & Teachers trust parents & 0,852 \\
\hline & Parents of students encourage good habits of study & 0,815 \\
\hline \multirow{4}{*}{$\begin{array}{l}\text { Factor 2: teachers views on students } \\
\text { (i) Mean: 5.15, SD: } 1.17 \\
\text { (ii) Cronbach Alpha: } 0.8207\end{array}$} & Teachers trust their students & 0,73 \\
\hline & Students can be counted on to do their work & 0,822 \\
\hline & Students are caring towards one another & 0,789 \\
\hline & Students respect those who get good results & 0,597 \\
\hline
\end{tabular}

${ }^{*}$ Based on questionnaire in Belfi et al. [22].

presents results of the factor analysis dealing with views on parents and teachers.

6.2.5. School Culture. The third component we used as an indication of the school's social capital referred to perceptions of its culture. Teachers were positive about three of the four school culture factors included in Table 8. This included the degree of shared responsibility and commitment to common goals, overall collaboration among staff, parent and to an extent student participation in school affairs, and a focus on inclusion and citizenship education. Fewer perceived that their schools tended to be shaped by individualism and lack of professional interactions.

Besides the above questions, we also asked teachers about school opportunities for professional development and the degree to which the school community felt bound by a common set of goals and mission. While 52.5\% felt that their school had a common mission, only $30 \%$ of teachers could say that in their school there was support for formal professional development.

\section{Teacher Collaboration and Differences in School Location and Type and Size of School}

We examined the relationship between factors differentiating teachers and their schools as well as their perceptions about collaboration. These factors covered teaching level, geographical location of the school, rural/urban condition, type of school management, and school size. We deal with them below.

7.1. Differences between Primary and Secondary Teachers. We found differences between primary and secondary level teachers. Primary level teachers significantly gave more importance to observing other teachers' lessons and using other colleagues' materials and to joint lesson preparation. They also participated more frequently in all types of schoolbased collaboration and differed significantly in this with secondary teachers, except in the only activity that was frequent for all groups (informal conversations with colleagues). Primary level teachers held significantly more positive views about students and parents in their schools than did secondary teachers. We found a significant difference in primary teacher ratings about their school culture, as they were significantly less prone to describe their schools as sites with rare discussion about professional topics or with individualist cultures than were secondary teachers. More so than secondary teachers they rated their school culture as collaborative and allowing more participation of students and parents in decision-making.

7.2. Geographical Location and Urban/Rural Differences. As indicated earlier in this article, the Metropolitan Region contrasts greatly in terms of population with the other two regions of Biobio and Araucanía. The Metropolitan Region has the largest spread of economic, cultural, and educational services and the known complexities of a metropolis. Biobio is a region that mixes industry and agriculture and its capital is the third largest city of the country. The Araucanía Region, in turn, is largely rural with a few small cities and concentrates a large part of the indigenous population of the country (Mapuches). We found significant differences between regions in terms of their beliefs about professional development (see Table 2). Teachers in the Metropolitan Region over those in the other two regions rated as important "working with colleagues" and learning from "reflection on cases and assessment results." On the other hand, in terms of actual engagement in collaborative activities (see Table 3), teachers in the Biobio and Araucanía regions more frequently engaged in mutual lesson observations compared to those in the Metropolitan Region.

In relation to beliefs in the schools' social capital (teachers, parents, and students; see Tables 6 and 7) as well as in the school culture (see Table 8 ) teachers in the Biobio and Araucanía regions held significantly more positive views than did their colleagues in the Metropolitan Region about students, participation of teachers in decision-making, and having a responsible and collaborative school culture.

We found significant differences between rural/multigrade and urban teachers in three dimensions: views about the role of parents and school culture (both indicators of schools' social capital; see Tables 7 and 8) and opportunities to participate in school-based collaboration (see Table 3). Compared to urban teachers those in rural schools held a 


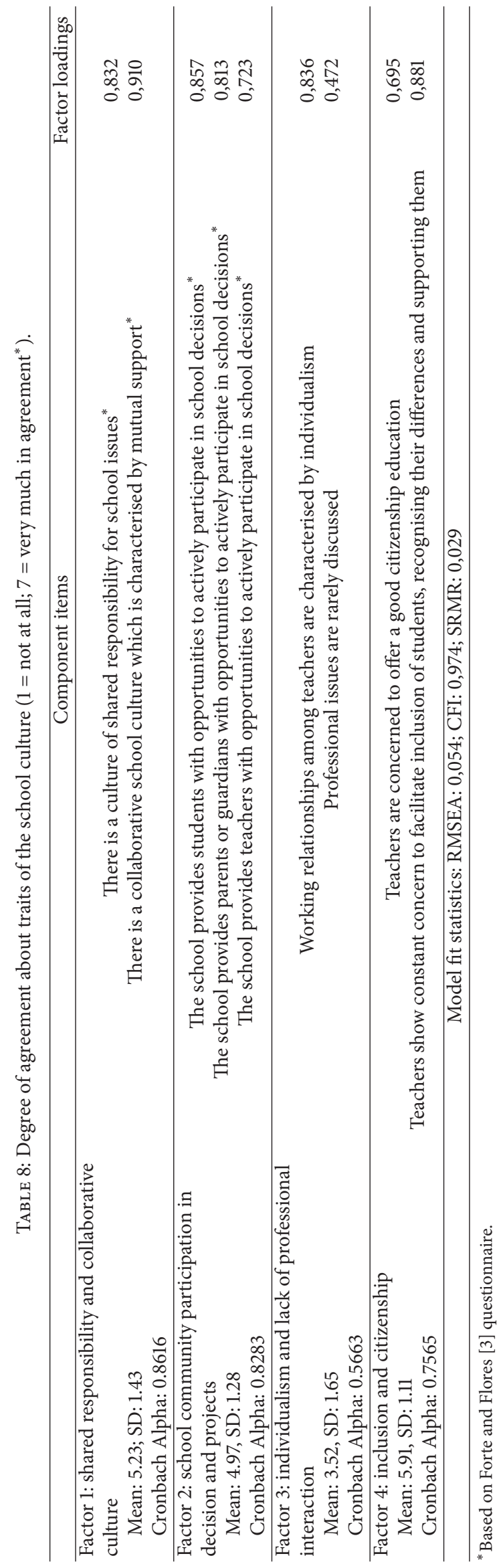


TABLE 9: Differences in teacher perceptions and collaboration experiences by size of school.

\begin{tabular}{|c|c|c|c|c|}
\hline & \multicolumn{2}{|c|}{ One class per grade } & \multicolumn{2}{|c|}{ More than one class per grade } \\
\hline & Mean & SD & Mean & $\mathrm{SD}$ \\
\hline School culture of shared responsibility and collaboration* & 5.4 & 1.34 & 5.08 & 1.44 \\
\hline Teacher, student and parent participation* & 5.15 & 1.22 & 4.83 & 1.31 \\
\hline Emphasis on inclusion and citizenship education* & 6.02 & 1.09 & 5.82 & 1.11 \\
\hline Actual observation of each other's lessons ${ }^{* *}$ & 3.25 & 1.46 & 2.77 & 1.40 \\
\hline
\end{tabular}

${ }^{*} 1=$ not important; 7 = very important; ${ }^{* *} 1=$ never; 6 = once a week or more.

higher concept of parents' contribution in all dimensions and rated their schools as having a responsible and collaborative culture with parent, teacher, and student opportunities to participate actively and for teacher/students to engage in the development of projects. Rural teachers also had significantly higher opportunity to observe each other's classes, engage in joint activities across different classes and age groups, work with other teachers to ensure common standards, and take part in reflective workshop meetings.

7.3. School Management Type. A remarkable finding resulted from comparing schools by type of management (municipal, private subsidised, and independent private). On the whole in Chile school management is highly correlated with student socioeconomic segregation [26]. Students from lower socioeconomic groups attend municipal schools and a proportion of private subsidised ones. As their socioeconomic conditions increase they attend more selective private subsidised schools and independent private schools. Given evidence showing a relationship between the schools' socioeconomic conditions and beliefs in their social capital [22], we would have expected municipal teachers to hold lower beliefs about their schools' social capital and culture and teacher collective efficacy. This was not the case. Although social capital perceptions did differ slightly among schools, they were only significant in relation to private schools. There were no significant differences between the other two types of schools. Also, teacher beliefs about professional development, teaching and learning, collective teacher efficacy, and collaborative culture did not differ significantly among the three types of school management.

7.4. School Size. We used as an indicator of school size the number of classes for each grade. As shown in Table 9 we found differences between school size and teacher perceptions about school culture and opportunities for teacher collaboration. On school culture teachers in schools with only one class per grade were significantly more positive in their perceptions, believing their school to have a culture of shared responsibility and collaboration. They also gave higher ratings to teacher, student, and parent participation in decisions and projects and to the school's emphasis on inclusion and citizenship education. In schools with only one class per grade, there were more opportunities for teacher collaborative activities involving the observation of each other's lessons.

We also compared the factor means of each school with total enrolment and found that, in schools with more than
300 students, there was less appreciation about the school community's opportunity to participate in decision-making and the role of parents and of the opportunities to collaborate among colleagues (as shown in Figure 2).

\section{Discussion}

On the basis of earlier research on Chilean teacher professionalism [31], the thrust of this study was to examine and interpret teacher views and experience regarding collegial collaboration as a source of learning and improvement. We knew about Chilean teachers' commitment to formal professional development given their efforts to engage in postcertification and masters' courses [31]. But we did not know whether they valued school-based learning from each other in the same way. We had evidence of actual teacher engagement in collaboration through TALIS 2013 [9], but not on how it might connect to beliefs about their colleagues' efficacy and school's capital and culture recognised as important factors in the literature $[3,21,22]$. Finally, while we assumed that systemic school conditions (public/private, urban/rural, and size) might affect possibilities for teacher collaboration, we did not know in what ways this might be so. We discuss our findings below.

\subsection{Professional Learning through Teacher Collaboration:} Views and Experience. Both in their concept of teacher collaboration as a form of professional learning and in their account of school-based opportunities for collaboration, Chilean teachers reflect what might be considered as the initial or weaker levels of collaboration within the continuum identified by Little [19] and the less complex collaborative activities as reviewed by Vangrieken et al. [1]. Thus, "preparing lessons with other colleagues" and "talking to other teachers regarding teaching problems" were considered as important forms of collaboration. However, teachers were reticent in granting the same degree of importance to activities involving "mutual classroom observation and feedback." In fact, these were forms of collaboration in which they were less frequently involved. On the other hand and on equal terms, teachers appreciated individual forms of professional development based on reflection such as "examining student work to see if a teaching approach worked" or "using data from my students' learning results to reorient my teaching." In this regard Chilean teachers seem to affirm professional autonomy more than value demanding collaborative work with other teachers, a condition also observed among teachers in Flanders [23]. 


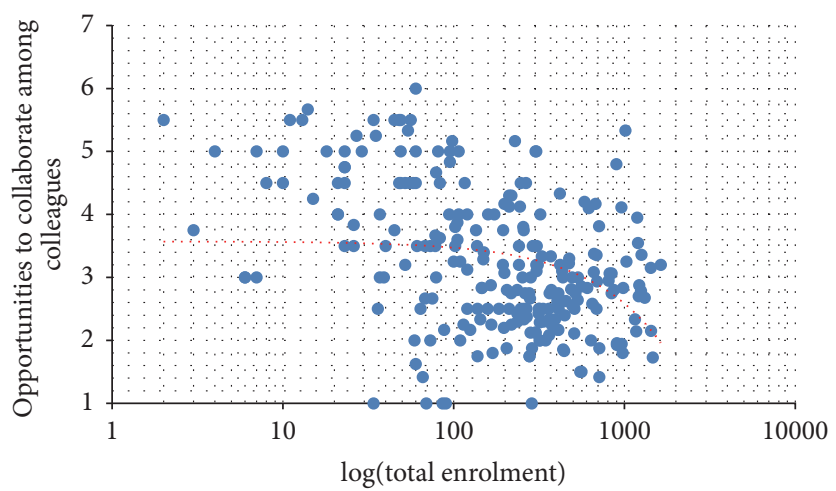

Figure 2: Teacher opportunity to collaborate with colleagues by school size.

There were grounds for affirming theoretically that the teachers studied might appreciate their school contexts as a source of professional learning. They held highly positive beliefs about the collective efficacy of their colleagues in terms of their capacity to handle students' needs and teach them accordingly. Teachers also had good perceptions of the student body in terms of their attitudes and effort, which potentially should elicit a desire to respond through professional improvement. But their views on parents' contribution to the social capital of their schools were more negative than might have been expected suggesting that teachers might be transferring to parents their own responsibility for student achievement. Furthermore, teacher beliefs related to school capital could have provided a basis for teachers to appreciate collaboration in communities of practice or in teams requiring interdependence and group autonomy $[19,32]$. And yet, as stated above, this was not the case except for a smaller proportion of the teachers we studied.

While the survey did not inquire about school-specific conditions affecting the opportunity to collaborate, respondents' perceptions about their school culture did not support the assumption that such cultures were at fault. On the whole, teachers" agreement about working in a "collaborative school culture characterised by mutual support" should have stimulated engagement in more complex forms of collaborative professional learning. Yet this was not the case as their most frequent collaborative activities were informal exchanges in the hallway and participation in "contrived" forms of collaboration $[3,33,34]$ such as "reviewing student standardised assessment results."

\subsection{Systemic Factors Affecting Teacher School-Based Collab-} oration. To explain the lesser involvement in demanding collaborative endeavours we refer to the working conditions of teachers in Chile (among the worst in OCDE countries), as these leave little nonteaching time to engage in such activities. This fact was corroborated during case study interviews that were part of the study. Interviews and visits to schools also pointed to spatial conditions and heavy timetables as inhibiting mutual classroom observation and feedback. These are factors also noted in international studies on teacher collaboration $[1,8,35]$. On the other hand, the lesser belief in the value of mutual classroom observation expressed by
Chilean teachers may well have to do with limited exposure of Chilean teachers to its benefits and to the longstanding tradition of closing their classrooms to outsiders

We did find differences in perceptions about school social capital and collaboration in terms of school geographical location and size, but not in relation to socioeconomic status of students. Teachers in the smaller regions of Biobio and Araucanía reported a more positive environment in terms of social capital and opportunity for higher-level forms of collaborative activities than did those in the Metropolitan Region. The effect of school size, operating as a proxy for quality of school culture and organizational conditions, was not surprising. Thus smaller schools or schools with one class per grade were those in which teachers had engaged more frequently in lesson observation and mutual feedback, were more appreciative of parent contribution, and had higher opportunity to participate in decision-making and to collaborate with colleagues. And, as for socioeconomic status of students largely associated in Chile with public/private management of schools, this was not a determinant factor for teacher beliefs and assessment of school capital and culture, although it may have affected their more negative view of parents.

The relationship between these systemic school factors and opportunities for teacher collaboration cannot simply be altered by means of grand policy adjustments. This suggests that increase in valuation and opportunity to collaborate in demanding teacher-related tasks requires teachers to grow in awareness of the benefits of these forms of collaboration and capacity to manage contextual limitations. This can occur through workshops and professional discussion groups focused on the benefits of collaboration for student learning and through the analysis of professional materials related to collaboration, such as those recently made available by the Chilean teachers' union [36]. It also may be assisted by inschool arrangements facilitated by the school and/or district leadership (in the case of municipalities) providing space, time, and opportunity for teacher engagement in demanding and rigorous forms of collaboration. We found examples of such arrangements in the case studies that are part of this study and that involved schools in the big city of Santiago (Metropolitan Region) and the smaller city of Chillán (Biobio Region) as well as in rural schools in Araucanía. 


\section{Some Conclusions}

In many ways the notion of collaboration is central to the teaching profession, ranging from beginning teacher requests for specific assistance, the sounding out of teaching ideas among colleagues, and the provision of tips for dealing with student issues to cross-disciplinary project planning and full engagement in school-based communities of practice. In general terms, teachers know and value this as shown in the study reported in this paper. In their responses to the survey Chilean teachers associate professional learning with collaboration, as do teachers in other national contexts. Furthermore, the fact of examining school-based teacher collaboration beliefs and experience in different Chilean geographical regions and types of schools and across school levels strengthened the recognition that some contextual conditions affect collaboration. Findings of the study provide a spotlight on collaboration as seen by teachers and, in line with other research, on the need to facilitate its occurrence through better organization of teacher time as well as through spatial and timetable arrangements that allow for encounter slots.

The design of the study allowed us to bring together different perspectives on teacher collaboration found in the literature and in that sense advance further towards connecting beliefs in colleagues and other school actors, school culture valuation, and professional understandings of teaching and learning with actual collaborative engagement possibilities in different external contexts. The study advances in the understanding of collaboration as intrinsic to teacher conceptions of their profession, but also as mediated in its quality and depth by teacher interpretations about effective and possible forms of collaboration in their concrete contexts.

Reporting of the study in this paper is limited and we are conscious and cautious that we only carried out bivariate comparisons involving a certain amount of factors and without considering interactions between these and inschool conditions. We found some results that agree with common sense perceptions such as the positive effect of being in a smaller school in terms of opportunity to engage in collaborative activities, but on the other hand we could not examine more specifically the differential effects of primary and secondary schools regarding forms of teacher collaboration. The case studies that are part of this project advance in this direction. Future research needs to study how collective efficacy, school capital, and professional development beliefs connect with professionally demanding forms of schoolbased collaboration.

Achieving educational results is essentially a collective process in which teachers and students engage, though strongly relying on teacher collegial endeavours. Teachers know this, and in this respect the findings of the study provide substance for valuing teacher professional views on collaboration as expressed in their occupational discourse [15]. The findings also provide policy-makers and school administrators with evidence to support collaboration in the more demanding and productive forms related to teacher professional growth and student learning.

\section{Conflicts of Interest}

The authors declare that they have no conflicts of interest.

\section{Acknowledgments}

The authors gratefully acknowledge funding from Chilean National Council of Science and Technology (CONICYT), Project Fondecyt 1150596, PIA-CONICYT Basal Funds for Centres of Excellence Project BF0003.

\section{References}

[1] K. Vangrieken, F. Dochy, E. Raes, and E. Kyndt, "Teacher collaboration: A systematic review," Educational Research Review, vol. 15, pp. 17-40, 2015.

[2] D. Richter, M. Kunter, U. Klusmann, O. Lüdtke, and J. Baumert, "Professional development across the teaching career: Teachers' uptake of formal and informal learning opportunities," Teaching and Teacher Education, vol. 27, no. 1, pp. 116-126, 2011.

[3] A. M. Forte and M. A. Flores, "Teacher collaboration and professional development in the workplace: a study of Portuguese teachers," European Journal of Teacher Education, vol. 37, no. 1, pp. 91-105, 2014.

[4] I. S. Horn and J. W. Little, "Attending to problems of practice: Routines and resources for professional learning in teachers' workplace interactions," American Educational Research Journal, vol. 47, no. 1, pp. 181-217, 2010.

[5] E. Jurasaite-Harbison and L. A. Rex, "School cultures as contexts for informal teacher learning," Teaching and Teacher Education, vol. 26, no. 2, pp. 267-277, 2010.

[6] E. Jurasaite-Harbison, “Teachers' workplace learning within informal contexts of school cultures in the United States and Lithuania," Journal of Workplace Learning, vol. 21, no. 4, pp. 299321, 2009.

[7] E. Kyndt, F. Dochy, and H. Nijs, "Learning conditions for nonformal and informal workplace learning," Journal of Workplace Learning, vol. 21, no. 5, pp. 369-383, 2009.

[8] M. C. Lohman, "Environmental inhibitors to informal learning in the workplace: A case study of public school teachers," Adult Education Quarterly, vol. 50, no. 2, pp. 83-101, 2000.

[9] OECD, New Insights From TALIS 2013. Teaching and Learning in Primary and Upper Secondary Education, (Paris, OECD), 2014.

[10] A. Schleicher, Teaching Excellence Through Professional Learning and Policy Reform. Lessons from Around the World. International Summit on the Teaching Profession, (Paris, OECD), 2016.

[11] B. Avalos, "School-based teacher development: the experience of teacher professional groups in secondary schools in Chile," Teaching and Teacher Education, vol. 14, no. 3, pp. 257-271, 1998.

[12] Ley 20.903 (2016). Crea el Sistema de Desarrollo Profesional Docente y Modifica Otras Normas (Santiago, Chile, Ministerio de Educación).

[13] OECD, Programme for International Student Assessment 2015, (Paris, OECD). https://www.oecd.org/pisa/aboutpisa/, 2016.

[14] IEA (2015), Trends in International Mathematics and Science Study (TIMSS), Amsterdam: IEA, http://www.iea.nl/timss2015-results.

[15] J. Evetts, "New Professionalism and new public management: Changes, continuities and consequences," Comparative Sociology, vol. 8, no. 2, pp. 247-266, 2009. 
[16] A. Hargreaves and M. Fullan, Professional Capital. Transforming Teaching in Every School, New York: Teachers College and; Toronto, Ontario Principals Council.

[17] S. Feiman-Nemser, Teachers as Learners, Harvard Education Press, Cambridge, Mass, USA, 2012.

[18] J. Calderhead and S. B. Shorrock, Understanding Teacher Education, Taylor \& Francis, Abingdon, UK, 1900.

[19] J. W. Little, "The persistence of privacy: autonomy and initiative in teachers professional relationships," Teachers College Record, vol. 91, no. 4, pp. 509-546, 1990.

[20] S. De Vries, W. J. C. M. Van De Grift, and E. P. W. A. Jansen, "How teachers beliefs about learning and teaching relate to their continuing professional development," Teachers and Teaching: Theory and Practice, vol. 20, no. 3, pp. 338-357, 2014.

[21] R. D. Goddard, W. K. Hoy, and A. Woolfolk Hoy, "Collective teacher efficacy: Its meaning, measure, and impact on student achievement," American Educational Research Journal, vol. 37, no. 2, pp. 479-507, 2000.

[22] B. Belfi, S. Gielen, B. De Fraine, K. Verschueren, and C. Meredith, "School-based social capital: The missing link between schools' socioeconomic composition and collective teacher efficacy," Teaching and Teacher Education, vol. 45, pp. 33-44, 2015.

[23] I. Grosemans, A. Boon, C. Verclairen, F. Dochy, and E. Kyndt, "Informal learning of primary school teachers: Considering the role of teaching experience and school culture," Teaching and Teacher Education, vol. 47, pp. 151-161, 2015.

[24] M. C. Lohman, "A survey of factors influencing the engagement of two professional groups in informal workplace learning activities," Human Resource Development Quarterly, vol. 16, no. 4, pp. 501-527, 2005.

[25] Ministerio de Educación de Chile (2015), Anuario Estadístico, (Santiago, Chile, Ministerio de Educación).

[26] C. Bellei, "El estudio de la segregación socioeconómica y académica de la educación chilena," Estudios pedagógicos (Valdivia), vol. 39, no. 1, pp. 325-345, 2013.

[27] S. De Vries, E. P. W. A. Jansen, and W. J. C. M. van de Grift, "Profiling teachers' continuing professional development and the relation with their beliefs about learning and teaching," Teaching and Teacher Education, vol. 33, pp. 78-89, 2013.

[28] T. A. Brown, Confirmatory Factor Analysis for Applied Research, The Guilford Press, London, England, 2006.

[29] L. J. Cronbach, "Coefficient alpha and the internal structure of tests," Psychometrika, vol. 16, no. 3, pp. 297-334, 1951.

[30] A. Bandura, "Self-efficacy: toward a unifying theory of behavioral change," Psychological Review, vol. 84, no. 2, pp. 191-215, 1977.

[31] B. Avalos, Héroes o Villanos: La Profesión Docente en Chile 2013, Editorial Universitaria, Santiago, Chile, 2013.

[32] J. J. Doppenberg, A. W. E. A. Bakx, and P. J. Den Brok, "Collaborative teacher learning in different primary school settings," Teachers and Teaching: Theory and Practice, vol. 18, no. 5, pp. 547-566, 2012.

[33] R. du Four, "Work together: But only if you want to," Phi Delta Kappan, vol. 92, no. 5, pp. 57-61, 2011.

[34] A. Hargreaves, "Contrived collegiality: the micropolitics of teacher collaboration," in The Politics of Life in Schools: Power, Conflict and Cooperation, 1991.

[35] C. Schechter, "The professional learning community as perceived by Israeli school superintendents, principals and teachers," International Review of Education, vol. 58, no. 6, pp. 717734, 2012.
[36] Docencia, Trabajo colaborativo. Base para el desarrollo profesional docente, Docencia 29 (60), 1-99, 2016. 


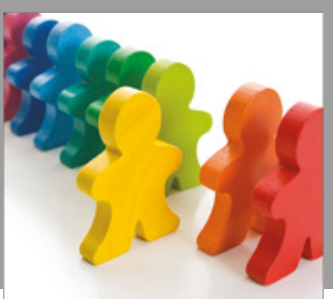

Autism

Research and Treatment
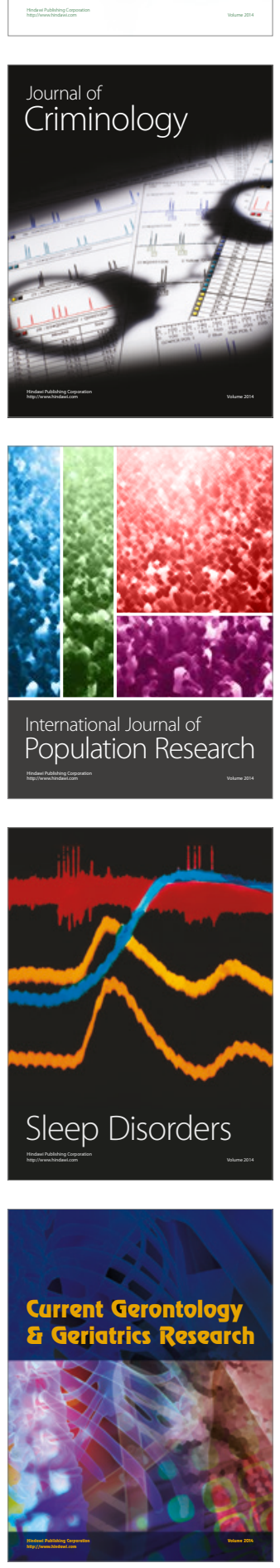

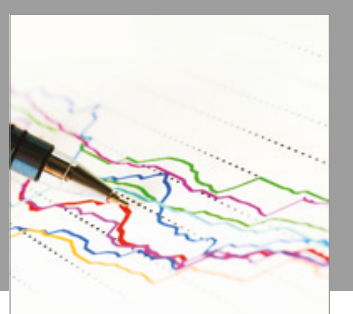

Economics

Research International

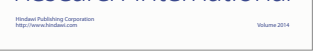

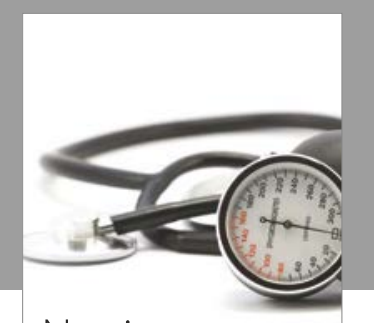

Nursing

Research and Practice

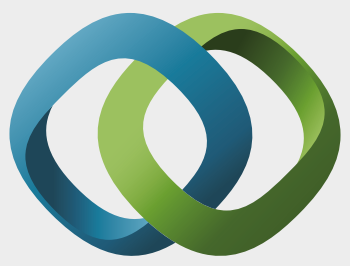

\section{Hindawi}

Submit your manuscripts at

https://www.hindawi.com
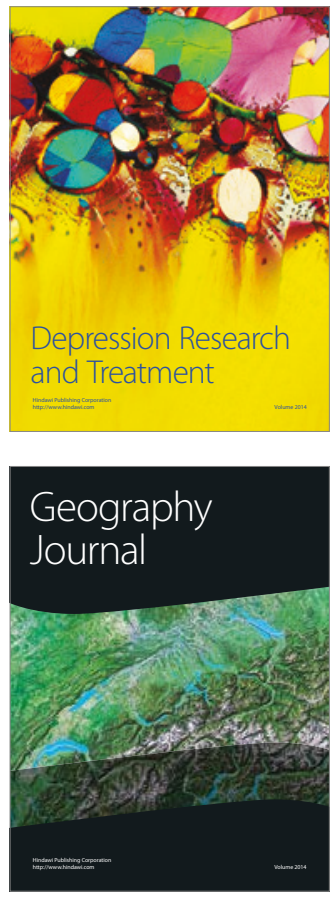
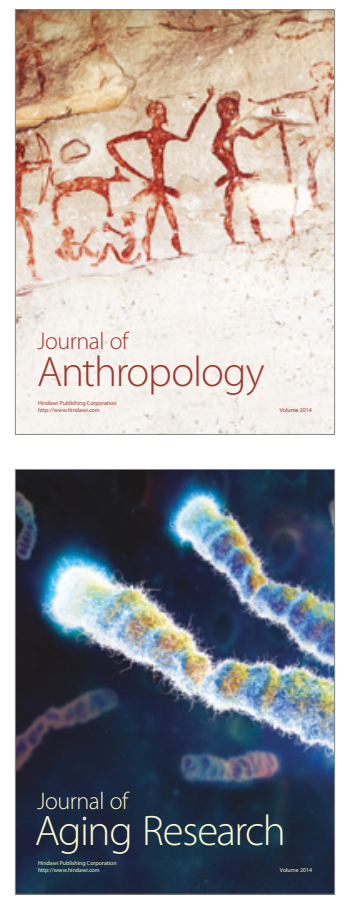
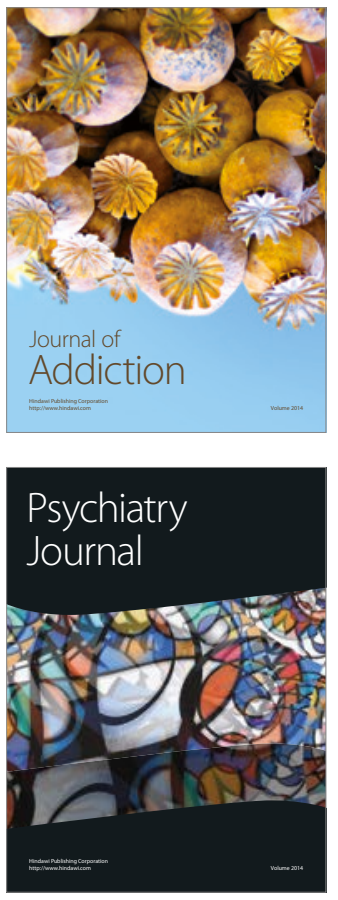

Child Development

Research

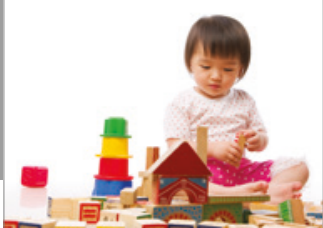

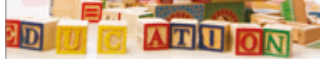
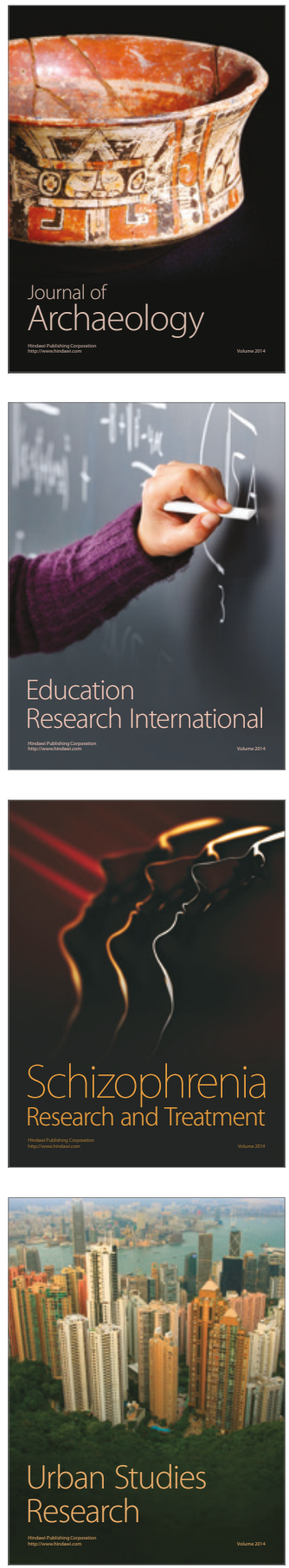